\title{
Physiological Effects of the Combined Stresses of Freeze-thaw, Acid Precipitation and Deicing Salt on Alfalfa Seedlings
}

Guozhang Bao ( $\sim$ baogz@jlu.edu.cn )

Jilin University

Wenyi Tang

Jilin University

Qirui An

Jilin University

Yaoxin Liu

Jilin University

Jiaqi Tian

Jilin University

Nan Zhao

Jilin University

Saning Zhu

Jilin University

\section{Research article}

Keywords: freeze-thaw, acid precipitation, deicing salt, combined stress, alfalfa

Posted Date: January 9th, 2020

DOI: https://doi.org/10.21203/rs.2.20458/v1

License: (9) (i) This work is licensed under a Creative Commons Attribution 4.0 International License.

Read Full License

Version of Record: A version of this preprint was published at BMC Plant Biology on May 11th, 2020. See the published version at https://doi.org/10.1186/s12870-020-02413-4. 


\section{Abstract}

\section{Background}

In the early spring of northern China, the combined stresses of freeze-thaw, deicing salt and acid deposition are the main ecological threats to the urban turf ecosystem.

\section{Results}

We studied changes in the Malondialdehyde (MDA), protein, soluble sugar, proline and chlorophyll contents of DongMu No. 1 seedlings of 8 treatment combination groups which are imposed by freezethaw $(F)$, acid rain $(A)$ and deicing salt $(D)$. An increasing in MDA content showed that the membrane system of seedlings was damaged under combined stress $(F+A+D)$. The changes indicated that under the adverse conditions, the proline and soluble sugar contents increased obviously with the accumulation of MDA in the plants, while the chlorophyll content decreased significantly.

\section{Conclusion}

Plants can alleviate the damage caused by stress by increasing soluble sugars and by regulating the proline content to maintain osmotic balance.

\section{Background}

Freeze-thaw refers to a physical geological phenomenon in which the soil layer freezes and melts due to the temperature falling below zero and rising above zero [1]. High latitudes have a cold winter climate, frequent snowfall and large snowfall. Deicing salt is widely used because it is relatively cheap. Deicing salts often enter the green plant belt in the form of runoff and splash and accumulate and penetrate plant roots, resulting in serious salt damage [2]. In addition, the extensive use of coal and oil, as well as the production of sulfur dioxide from coal burning during winter in northern China, can cause acid rain hazards. After North America and Europe, China is the third largest acid deposition area in the world, and the area subjected to acid rain is increasing rapidly [3].

Alfalfa is a perennial herb of the family Leguminosae. Artificial turf is widely cultivated in high latitudes in China. During winter at high latitudes, freeze-thaw and deicing salt tend to accompany each other, and due to the large amount of coal heating, acid deposition occurs due to increased sulfur dioxide. Consequently, alfalfa, a green grass species, often freezes and thaws and is also subjected to stresses imposed by deicing salt and acid deposition. Research on the resistance of alfalfa mostly includes individual factors [4]; however, in the actual environment, plants are often affected by multiple factors. In this experiment, alfalfa was used as the experimental material to study changes in the MDA, protein, soluble sugar, proline and chlorophyll contents of seedlings subjected to combined stresses, i.e., acid rain and deicing salt, under freeze-thaw conditions, aiming to explore the resistance of alfalfa. The results 
from this study provide a theoretical basis for the evaluation of cold, salt and acid resistance and the reasonable use of deicing salt in high latitudes.

\section{Results}

\section{Changes in the MDA content}

MDA is one of the main products of membrane peroxidation and can strongly react with various components in the cell, causing damage to enzymes and plasma membranes, leading to membrane structure damage and impaired physiological function [5]. Fig. 1 shows that during the freezing period, the MDA content in the $\mathrm{F}$ group and the combined stress group increased and peaked at $-3^{\circ} \mathrm{C}$. The MDA content of the $A+F$ group, the $D+F$ group and the $A+D+F$ groups was higher than that of the blank control group, i.e., by $8.03 \sim 61.40 \%, 45.55 \sim 107.25 \%$ and $61.01 \sim 138.07 \%$, respectively. This indicates that combined stresses cause more intense stress conditions, which resulted in more MDA in the alfalfa plants.

During the freeze-thaw period, the MDA content measured in the seedlings of the combined stress and freeze-thaw groups showed a downward trend. When the temperature was increased to $10^{\circ} \mathrm{C}$, the content of MDA in the $D+F, A+F$ and $A+D+F$ groups decreased by $31.87 \%, 57.77 \%$ and $69.73 \%$, respectively, compared to that measured 142 at $-3^{\circ} \mathrm{C}$. It also can be observed from Fig. 1 that the combined stresses resulted in a more significant effect than the individual low-temperature stress treatment, which is consistent with published experimental results on the effects of low-temperature stress on plant physiological indexes $[6,7]$.

\section{Changes in the protein content}

According to Fig. 2, the protein content in the combined stress group and the freeze-thaw group was significantly lower than that in the blank control group throughout the whole freeze-thaw cycle. This may be due to the adverse conditions that reduced the activity of protein synthetase or increased the activity of the enzyme in the plant, resulting in a decrease in the protein content. This result is similar to that presented by Gilmour et al. [8]. During the freezing period, the protein content of the combined stress group and the freeze-thaw group reached a peak at $0^{\circ} \mathrm{C}$, and that of each test group showed a downward trend from 0 to $-3^{\circ} \mathrm{C}$, indicating that low temperature decreased the plant protein content. This is consistent with the existing research results [9].

During the freeze-thaw period, the protein content of the A+D+F group decreased initially and then slowly increased, reaching the lowest value at $0^{\circ} \mathrm{C}$. The reason may be that plants start to grow slowly and consume protein when warming up. At a temperature higher than $0^{\circ} \mathrm{C}$, the protein content of each group showed a steady or slightly decreasing trend, which is similar to the results of Fleck et al., who investigated protein accumulation in winter wheat leaves and their freeze resistance [10]. During this period, higher protein content was measured in the freeze-thaw group than in the combined stress group, 
indicating that the combined stress caused more damage to the plants, resulting in slower recovery when the temperature increased.

\section{Changes in the soluble sugar content}

It can be observed from Fig. 3 that the soluble sugar content of each test group was significantly higher than that of the blank control group throughout the freeze-thaw cycle. This may have occurred because plants under stress conditions protect themselves by accumulating soluble sugars, similar to the findings of Kaufmann and Blanke [11]. During the freeze-thaw period, the soluble sugar content of each test group increased, reaching a peak at $-3^{\circ} \mathrm{C}$. The results show that in the low-temperature environment, the soluble sugar content in the plants increased significantly, and the plants protected themselves by accumulating a large amount of soluble sugar. The highest soluble sugar content was measured in plants subjected to the freeze-thaw + deicing salt + acid rain combined stress condition.

During the freeze-thaw period, the soluble sugar content of each test group showed a downward trend. Specifically, during the temperature change from $-3^{\circ} \mathrm{C}$ to $0^{\circ} \mathrm{C}$, the soluble sugar contents of the $\mathrm{F}$ group and the $A+D+F$ group differed significantly (by $26.68 \sim 30.12 \%$ ), but the soluble sugar content of the two other groups did not differ significantly from that of the freeze-thaw group. The findings indicated that the conditions resulting from the combination of the three stress factors caused the most damage to the plants.

\section{Changes in the proline content}

As shown in Fig. 4, the proline content in the test group was higher than that in the control group throughout the whole freeze-thaw period. This is consistent with the research results of Hare et al., who analyzed the cumulative effect of osmotic pressure under stress conditions [12]. The resistance of alfalfa seedlings to stress caused by acid rain and deicing salt resulted in an increase in the proline content in vivo. During the freeze-thaw period, the proline content in the freeze-thaw group and in the combined stress group increased and peaked at $-3^{\circ} \mathrm{C}$; the following values were measured: $F$ group: $64.1 \mu \mathrm{g} / \mathrm{g} ; A+F$ group: $70.4 \mu \mathrm{g} / \mathrm{g}$; D+F group: $69.2 \mu \mathrm{g} / \mathrm{g}$; A+D+F group: $76.4 \mu \mathrm{g} / \mathrm{g}$, and compared with $10^{\circ} \mathrm{C}$, the proline content these respective values were $91.34 \%, 86.24 \%, 96.59 \%$ and $96.40 \%$ higher. This is consistent with the research results of Xin and Browse, that is, plants resist low-temperature damage by regulating the proline content [13].

During the freeze-thaw period, the proline content decreased with increasing temperature. Specifically, the proline content was $19.97 \%, 18.46 \%, 19.80 \%$ and $8.38 \%$ lower in the respective test groups (according to the above-mentioned order) at $-3^{\circ} \mathrm{C}$ compared with that measured at $0^{\circ} \mathrm{C}$. During the freeze-thaw period, the proline content was $16.10 \sim 40.38 \%$ higher in the A+D+F group than that in the group subjected to only freeze-thaw. This indicates that compared with freeze-thaw stress, the combined stresses resulted in more severe conditions, to which the plants responded by producing more proline to protect themselves. 
As shown in Fig.5, during the freeze-thaw period, the chlorophyll content of each experimental group exhibited an initial decrease followed by an increase. The chlorophyll content of the alfalfa decreased under low-temperature stress. During the freeze-thaw period, the chlorophyll content in all groups exhibited a downward trend and reached the minimum value at $-3^{\circ} \mathrm{C}$, i.e., in the $\mathrm{F}$ group, the $\mathrm{A}+\mathrm{F}$ group, the $D+F$ group, and the $A+D+F$ group, the values were $22.38 \%, 12.76 \%, 11.08 \%$ and $17.79 \%$ lower, respectively, than those measured at $10^{\circ} \mathrm{C}$.

During the freeze-thaw period, the chlorophyll content in the control group and the experimental groups showed an upward trend. Compared to the values measured at $-3^{\circ} \mathrm{C}$, significantly higher values, i.e., increases of $41.64 \%, 25.59 \%, 25.76 \%$, and $20.64 \%$, respectively, were measured at $10^{\circ} \mathrm{C}$. However, there was no significant difference in the chlorophyll content among the experimental groups throughout the whole freeze-thaw period. Low temperature is the main factor that affects alfalfa photosynthesis. This is consistent with the published results of the effect of low-temperature stress on the chlorophyll content of herbage [14-16].

\section{Correlation analysis between indexes}

Table 1 shows that under the freeze-thaw condition, MDA and proline were significantly positively correlated. MDA was positively correlated with soluble sugar, proline was positively correlated with soluble sugar. Chlorophyll was negatively correlated with all three indexes. There was no significant correlation between protein and the other indicators. This indicates that both proline and the soluble sugar content increased with the accumulation of MDA in plants under external stress, while the chlorophyll content decreased.

The correlations between the indexes of the freeze-thaw + acid rain + deicing salt group were similar to those of the freeze-thaw group, but all correlations were highly significant in the former group. The results showed that the combined stresses of freeze-thaw, acid rain and deicing salt resulted in more obvious changes in the plant physiological indexes, and the correlations between indexes were highly significant.

\section{Discussion}

\section{Effects of combined stresses on the membrane system}

MDA, one of the products of membrane lipid peroxidation in plants under adverse conditions, causes cross-linking polymerization of macromolecules such as proteins and nucleic acids [17], and its content is closely related to the degree of damage of the cell membrane system [18]. The degree of damage caused to membrane has been characterized [19]. In the complex stress environment of freezing and thawing, acid rain and chloride salt (snow-melting agent), membrane lipid peroxidation of plant cells caused MDA accumulation. The damage caused to the cell membrane when the seedlings were under stress resulted in an increase in the MDA content. The change in the MDA content in the A+D+F group was most obvious at $-3^{\circ} \mathrm{C}$. It is possible that the combined stresses of acid rain and deicing salt in the low-temperature environment had stronger physiological effects on the seedlings. The MDA content in 
plants increases with the degree of stress. The MDA content reflected the degree of damage caused to the plants by the combined stresses.

\section{Effect of combined stresses on osmotic adjustment substances}

Protein is the material basis of life, the most abundant organic macromolecule in plan cells, the basic organic matter that constitutes cells, and the main component of enzymes that can participate in the chemical reaction of cells [20]. During the freezing period, the protein content of the A+D+F group was lower than that of the blank group. This is an adverse condition that reduces the activity of protein synthetase or the activity of other plant enzymes, resulting in a decrease in the protein content. During the freeze-thaw period, the protein content was significantly lower than during the freezing period, indicating that the plants begin to grow and consume protein during the heating process. Moreover, the protein content of the $A+D+F$ salt group was lower than that of the other test groups, which indicated that the combined stresses had a strong inhibitory effect on the protein synthase activity in plants during the heating process.

Free proline is an important osmotic regulator in plants. Under stress conditions, the proline mass ratio in plant cells is greatly increased, which reduces the cell osmotic potential, helps cells to absorb water, and has protective effects related to protoplasm and protein molecules. Proline removes active oxygen, which improves the stress resistance of plants. A change in the proline content can be used as an indicator of cold resistance of plants [13]. The results of this experiment showed that the proline content of all groups was significantly increased in the low-temperature environment. This shows that proline, as an osmotic adjustment substance, can protect protein molecules and increase the cold resistance of plants. In this experiment, the proline content in the $A+D+F$ group was higher than that in the other groups, indicating that multiple stresses caused more damage to seedlings, which was due to the regulatory effect of proline. The in vivo permeability imbalance caused by the combined stresses was also resistant to the low-temperature environment.

Soluble sugar plays an important role in the growth cycle of plants. After plants are subjected to lowtemperature stress, the soluble sugar content increases, the cell fluid concentration increases, the freezing point is lowered, excessive dehydration of cells is reduced, and the protoplasm colloid is protected from cold coagulation, thus showing adaptability to low-temperature stress [21,22]. This experimental study found that in the low-temperature environment, the soluble sugar content of the test group and the control group increased significantly, which indicates that plants protect themselves by accumulating a large amount of soluble sugar under low-temperature conditions. The soluble sugar content of the A+D+F group was much higher than that of the control group because soluble sugar is related to the osmotic pressure-regulating mechanism in plants, and complex stress results in the accumulation of a large amount of soluble sugar for plant protection. It activates the osmotic pressure regulation mechanism in plants, and more soluble sugar is secreted to resist combined stresses.

Effect of combined stresses on chlorophyll 
The chlorophyll content will directly affect the photosynthetic intensity and the rate of material synthesis. Exogenous stress can reduce plant growth by reducing the chlorophyll content, changing the ultrastructure of chloroplasts, and inhibiting photosynthesis [23]. The results from this study indicated that the chlorophyll content of the control and experimental groups was low in the low-temperature environment; however, there was no significant difference between the groups, indicating that temperature had a strong influence on the chlorophyll content compared with the multiple stresses, which had little impact.

\section{Conclusions}

The results of this study showed that under the combined stresses of freeze-thaw, acid rain and deicing salt, the MDA content in the alfalfa seedlings increased, the protein content decreased, the reactive oxygen species increased, and the cell membrane system was damaged. Plants maintain osmotic balance by secreting soluble sugars and other defenses in response to superoxide anion damage caused to plants and by regulating the proline content. Under the experimental conditions, alfalfa continued to grow, indicating that it has certain acid, cold and salt tolerance.

\section{Methods}

\section{Plant materials}

The seeds of Dongmu-70 provided by the Life Sciences of Northeast Normal University of China were selected and soaked with $0.1 \%$ acidic $\mathrm{KMnO}_{4}$ solution for $2 \mathrm{~h}$ at first, and rinsed with distilled water, and then seeds were arranged onto trays covered with 2 - layer of filter paper and added with appropriate amount of nutrient solution. After the seeds germinated under dark condition at $20^{\circ} \mathrm{C}$ for $24 \mathrm{~h}$ in the MGC - 450BP light incubator, the full and similar sized seeds were picked and sprouted, then neatly spread on trays of $26 \times 18 \mathrm{~cm}$ (length $\times$ width) with seeds (40 seeds per line $\times 23$ lines) and then they were put in MGC - 450BP light incubator for germination, with $12 \mathrm{~h}$ light $\left(25^{\circ} \mathrm{C}\right)$ and $12 \mathrm{~h}$ non - light $\left(15^{\circ} \mathrm{C}\right)$ for a week, $80 \mathrm{ml}$ of nutrient solution was given every day, $40 \mathrm{~mL}$ each morning and evening.

\section{Acid rain and deicing salt application}

A deicing salt solution $(0.1 \mathrm{~mol} / \mathrm{L}, 1000 \mathrm{ml})$ and an acid rain solution $(\mathrm{pH}=4.5$ (sulfuric acid: nitric acid=3:1), $1000 \mathrm{ml}$ ) were prepared and set aside. Then the seedlings to be treated were divided into eight groups on average, which were recorded as $A+D+F, A+D, D+F, D, A+F, A, F$ and blank groups. $7 \mathrm{ml}$ of acid rain and $18 \mathrm{ml}$ of deicing salt were added to $A+D+F$ and $A+D$, respectively; $7 \mathrm{ml}$ of acid rain and $18 \mathrm{ml}$ of distilled water were added to $A$ and $A+F$, respectively; $18 \mathrm{ml}$ of deicing salt and $7 \mathrm{ml}$ of distilled water were added to $D$ and $D+F$, respectively; and corresponding volumes of distilled water were added to $F$ and blank groups, respectively. After the reagents were added, all the test groups were placed in a light incubator for 48 hours and were take out for freeze-thaw treatment. 
$A+D+F \square D+F \square A+F$ and $F$ were subjected to the freeze-thaw treatment, the seedlings were put into BPHJ $120 \mathrm{~A}$ high - low temperature test chamber to carry out a freeze-thaw cycle for a period of $14 \mathrm{~h}$, with the constant temperature curve set at $10,5,0,-5,0,5$ and $10{ }^{\circ} \mathrm{C}(\mathrm{T} 1 \sim \mathrm{T} 7)$, while the non - freeze - thaw treatments were maintained in the MGC - 450BP light incubator. The initial setting temperature of the $\mathrm{BPHJ}$ - 120A high - low temperature test chamber was $15^{\circ} \mathrm{C}$ which was close to room temperature at night. The temperature dropped steadily to $-5^{\circ} \mathrm{C}$ at a speed of $0.5^{\circ} \mathrm{C}$ every $12 \min$ (about $0.04{ }^{\circ} \mathrm{C} / \mathrm{min}$ ), and then the temperature rose from -5 to $10{ }^{\circ} \mathrm{C}$ at a speed of $0.5^{\circ} \mathrm{C}$ every $12 \mathrm{~min}$ (about $0.04{ }^{\circ} \mathrm{C} / \mathrm{min}$ ). At each temperature, samples were taken from freeze - thaw treatments and non - freeze - thaw treatments at random according to the required amount of the measurement.

\section{Determination of organic matter content}

Malondialdehyde (MDA) content was measured with thiobarbituric acid (TBA) chromatometry method. To extract MDA, leaf samples $(0.5 \mathrm{~g})$ were ground in liquid nitrogen, homogenized into $5 \mathrm{ml}$ of $10 \%$ trichloroacetic acid (TCA) solution, and centrifuged at $4000 \mathrm{r} \cdot \mathrm{min}^{-1}$ for $10 \mathrm{~min}$ at first. Then, $2 \mathrm{~mL}$ of centrifugal supernatant was absorbed to tubes, adding $2 \mathrm{~mL} 0.6 \%$ TBA solution, mixing them in a hat bath for $15 \mathrm{~min}$ and cooled to room temperature quickly, absorbance under 450, 532 and $600 \mathrm{~nm}$ was measured at last.

The content of soluble protein was determined by Coomassie brilliant blue method [24]. Leaves $(0.1 \mathrm{~g})$ were extracted by grinding with deionizer water $(5 \mathrm{ml})$, centrifuged for 10 minutes at $3000 \mathrm{r} / \mathrm{min}$ and diluted 5 times by supernatant $(1 \mathrm{ml})$. The diluted solution was shaken with $1 \mathrm{ml}$ and $5 \mathrm{ml}$ Coomassie brilliant blue. The absorbance (UV-6100 UV-Vis spectrophotometer) was measured at $595 \mathrm{~nm}$ after 2 minutes, and the protein content was determined by standard curve [25].

The proline content was determined by acid ninhydrin colorimetry method. Weigh $0.5 \mathrm{~g}$ of the sample into the test tube, add $5 \mathrm{ml}$ of $3 \%$ salicylic acid solution for $10 \mathrm{~min}$, then centrifuge at $3000 \mathrm{r} \cdot \mathrm{min}-1$ for $10 \mathrm{~min}$, absorb $2 \mathrm{ml}$ of supernatant, add $2 \mathrm{ml}$ of ice. Acetic acid and $3 \mathrm{ml}$ of an acid ninhydrin color developing solution with a mass fraction of $2.5 \%$. Extraction with $5 \mathrm{ml}$ of toluene and colorimetric determination at a wavelength of $520 \mathrm{~nm}$.

Chlorophyll content was measured by SPAD-502 Plus chlorophyll meter.

\section{Data processing}

The experimental data were graphed with Microsoft (Redmond, USA) Excel, and statistical analysis was performed with SPSS 16.0 statistical software (IBM SPSS Statistics, Chicago, USA) using single factor variance analysis (one-way analysis of variance) and multiple comparisons with least significant difference (LSD). The significance level was at 0.05 , the experiments were repeated five times, and all of the results are presented as mean $\pm \mathrm{SE}$.

\section{Abbreviations}


MDA: malondialdehyde; TBA: thiobarbituric acid; TCA: trichloroacetic acid

\section{Declarations}

Ethics approval and consent to participate: Not applicable.

Consent for publication: Not applicable.

Availability of data and materials: Data sharing is not applicable to this article as no datasets were generated or analysed during the current study.

Competing interests: The authors declare that they have no competing interests.

Funding: This work was supported by the National Natural Science Foundation of China under Grant No. 31772669. The funding bodies were not involved in the design of the study, collection, analysis, and interpretation of data, and in writing the manuscript.

Acknowledgements: Not applicable.

\section{References}

1. Du ZY, Cai YJ, Wang XD, Yan Y, Lu XY, Liu SZ. Research progress on the effects of soil freeze-thaw on plant physiology and ecology. Chinese Journal of Eco-Agriculture. 2014;22(01):1-9.

2. Dai HL, Zhang KL, Xu XL, Yu HY. Evaluation on the Effects of Deicing Chemicals on Soil and Water Environment. In: Yang Z, Chen B, editors. 18th Biennial Isem Conference on Ecological Modelling for Global Change And Coupled Human And Natural System. Procedia Environmental Sciences. 132012. p. 2122-30.

3. Larssen T, Lydersen E, Tang DG, He Y, Gao JX, Liu HY, et al. Acid rain in China. Environmental Science \& Technology. 2006;40(2):418-25.

4. Bertrand A, Bipfubusa M, Claessens A, Rocher S, Castonguay Y. Effect of photoperiod prior to cold acclimation on freezing tolerance and carbohydrate metabolism in alfalfa (Medicago sativa L.). Plant Science. 2017;264:122-8.

5. Zou Q. Experimental instruction of plant physiology. 1st ed. Beijing: China Agriculture Press; 2000.

6. Smart RE. Rapid estimates of relative water content. Plant physiology. 1974;53(2):258-60.

7. Marcum KB, Pessarakli M. Salinity Tolerance of Ryegrass Turf Cultivars. Hortscience. 2010;45(12):1882-4.

8. Bian WJ, Bao GZ, Qian HM, Song ZW, Qi ZM, Zhang MY, et al. Physiological Response Characteristics in Medicago sativa Under Freeze-Thaw and Deicing Salt Stress. Water Air And Soil Pollution. 2018;229(6).

9. Zhang JY, Duan Z, Zhang DY, Zhang JQ, Di HY, Wu F, et al. Co-transforming bar and CsLEA enhanced tolerance to drought and salt stress in transgenic alfalfa (Medicago sativa L.). Biochemical And 
Biophysical Research Communications. 2016;472(1):75-82.

10. Gilmour SJ, Sebolt AM, Salazar MP, Everard JD, Thomashow MF. Overexpression of the Arabidopsis CBF3 transcriptional activator mimics multiple biochemical changes associated with cold acclimation. Plant Physiology. 2000;124(4):1854-65.

11. Karimzadeh G, Darvishzadeh R, Jalali-Javaran M, Dehghani H. Cold-induced accumulation of protein in the leaves of spring and winter barley cultivars. Acta Biologica Hungarica. 2005;56(1-2):83-96.

12. Fleck RA, Day JG, Clarke KJ, Benson EE. Elucidation of the metabolic and structural basis for the cryopreservation recalcitrance of Vaucheria sessilis. Cryo-Letters. 1999;20(5):271-82.

13. Kaufmann $\mathrm{H}$, Blanke M. Changes in carbohydrate levels and relative water content (RWC) to distinguish dormancy phases in sweet cherry. Journal Of Plant Physiology. 2017;218:1-5.

14. Hare PD, Cress WA, Van Staden J. Dissecting the roles of osmolyte accumulation during stress. Plant, Cell \& Environment. 1998;21(6).

15. Xin Z, Browse J. Cold comfort farm: the acclimation of plants to freezing temperatures. Plant Cell Environ. 2000;23(9):893-902.

16. Aroca R, Irigoyen JJ, Sanchez-Diaz M. Photosynthetic characteristics and protective mechanisms against oxidative stress during chilling and subsequent recovery in two maize varieties differing in chilling sensitivity. Plant Science. 2001;161(4):719-26.

17. Strand M, Öquist G. Effects of frost hardening, dehardening and freezing stress on in vivo chlorophyll fluorescence of seedlings of Scots pine (Pinus sylvestris L.). Plant, Cell \& Environment. 1988;11(4):231-8.

18. Georgieva K, Lichtenthaler HK. Photosynthetic activity and acclimation ability of pea plants to low and high temperature treatment as studied by means of chlorophyll fluorescence. Journal Of Plant Physiology. 1999;155(3):416-23.

19. Huff A. Peroxides-catalysed oxidation of chlorophyll by hydrogen peroxide. Phytochemistry. 1982;21(2):261-5.

20. Zhang EP, Zhang SH, Si LT, Pang JA, Ma DH. Effects of NaCl stress on the membrance lipid peroxidation in cotyledon of cucumber seedlings. Journal of Shenyang Agricultural University. 2001(06):446-8.

21. Dhindsa SR, Plumb-Dhindsa LP, Reid MD. Leaf senescence and lipid peroxidation: Effects of some phytohormones, and scavengers of free radicals and singlet oxygen. Physiologia Plantarum. 1982;56(4):453-7.

22. Wang XK. Principles and techniques of plant physiological and biochemical experiments. 2 nd ed. Beijing: Higher Education Press; 2006.

23. Liu ZQ, Zhang SC. Plant Resistance Physiology. Beijing: China Agriculture Press; 1994.

24. Wang Z. Plant Physiology. Beijing: China Agriculture Press; 2010.

25. Shahabivand S, Parvaneh A, Aliloo AA. Root endophytic fungus Piriformospora indica affected growth, cadmium partitioning and chlorophyll fluorescence of sunflower under cadmium toxicity. 
Ecotoxicology And Environmental Safety. 2017;145:496-502.

\section{Table}

Table 1 Correlation analysis of physiological indexes of alfalfa seedlings under freeze-thaw and combined stresses

\begin{tabular}{ccccccc}
\hline & & MDA & protein & chlorophyll & proline & soluble suger \\
\hline Freeze-Thaw & MDA & 1.000 & & & & \\
Group & protein & 0.090 & 1.000 & & & \\
& chlorophyll & $-0.867^{*}$ & -0.348 & 1.000 & & \\
& proline & $0.887^{* *}$ & 0.270 & $-0.904^{* *}$ & 1.000 & \\
& soluble suger & $0.781^{*}$ & 0.016 & $-0.761^{*}$ & $0.855^{*}$ & \multirow{2}{*}{1.000} \\
\cline { 2 - 7 } Freeze-Thaw & MDA & 1.000 & & & & \\
+ +Acid Rain & protein & -0.153 & 1.000 & & & \\
+ deicing salt & chlorophyll & $-0.904^{* *}$ & 0.296 & 1.000 & & \\
Group & proline & $0.946^{* *}$ & -0.291 & $-0.936^{* *}$ & 1.000 & \\
& soluble suger & $0.895^{* *}$ & -0.261 & $-0.947^{* *}$ & $0.921^{* *}$ & \multirow{2}{*}{1.000} \\
\hline
\end{tabular}

** indicates a significant correlation at the 0.01 level;

* indicates a significant correlation at the 0.05 level.

\section{Figures}




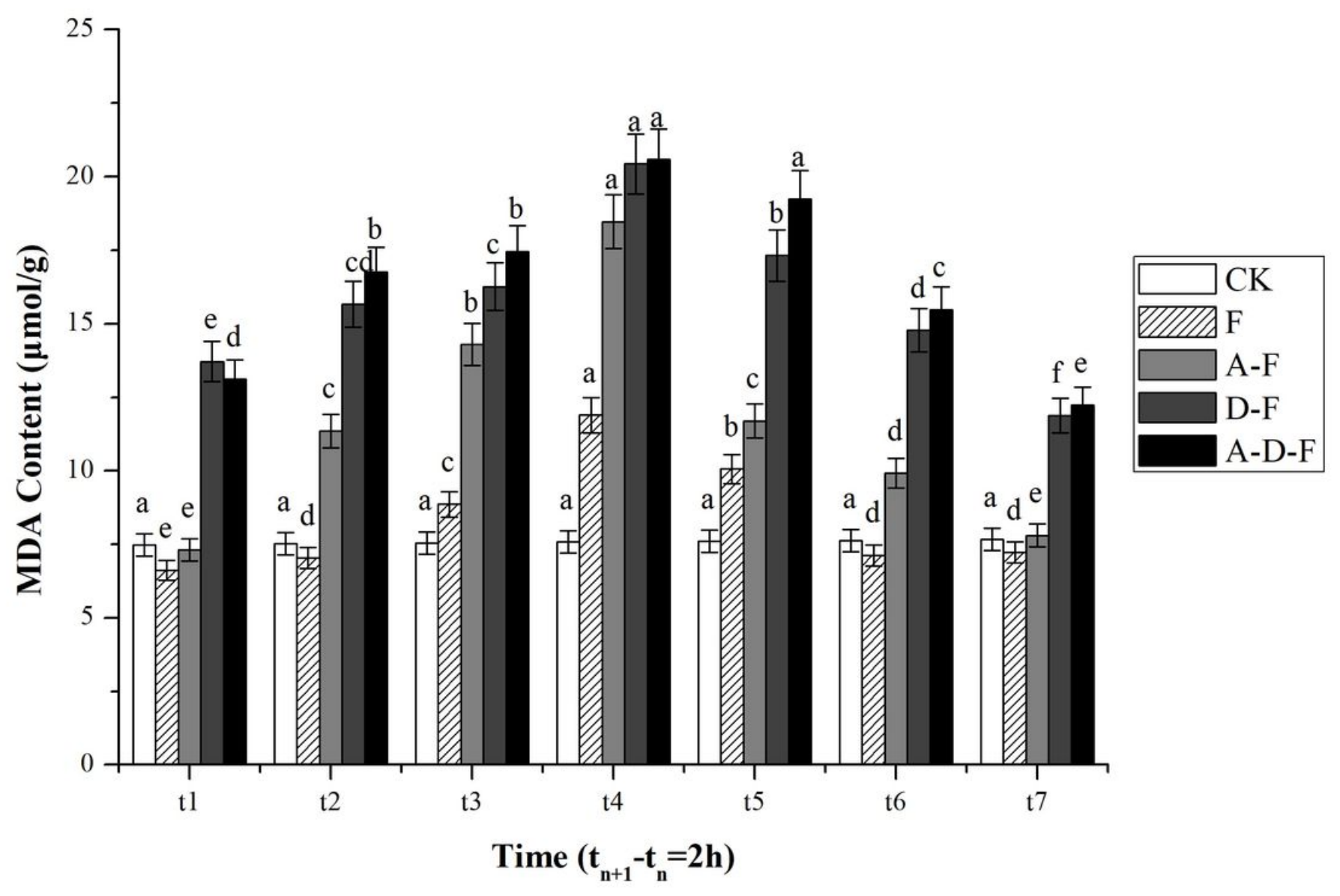

Figure 1

Combined effects of freeze-thaw, deicing salt and acid rain on the MDA content of alfalfa seedlings (mean $\pm S E, n=3$ ). $t 1 \sim t 7$ represents different $2 \mathrm{~h}$ temperature interval corresponding to $10,5,0,-5,0,5$, and $10^{\circ} \mathrm{C}$. CK represent blank group. The letter $A, D$ and $F$ represented acid rain treatment, deicing salt treatment and freeze-thaw treatment, respectively. The different letters indicate significant differences among the various treatments $(P<0.05)$. 


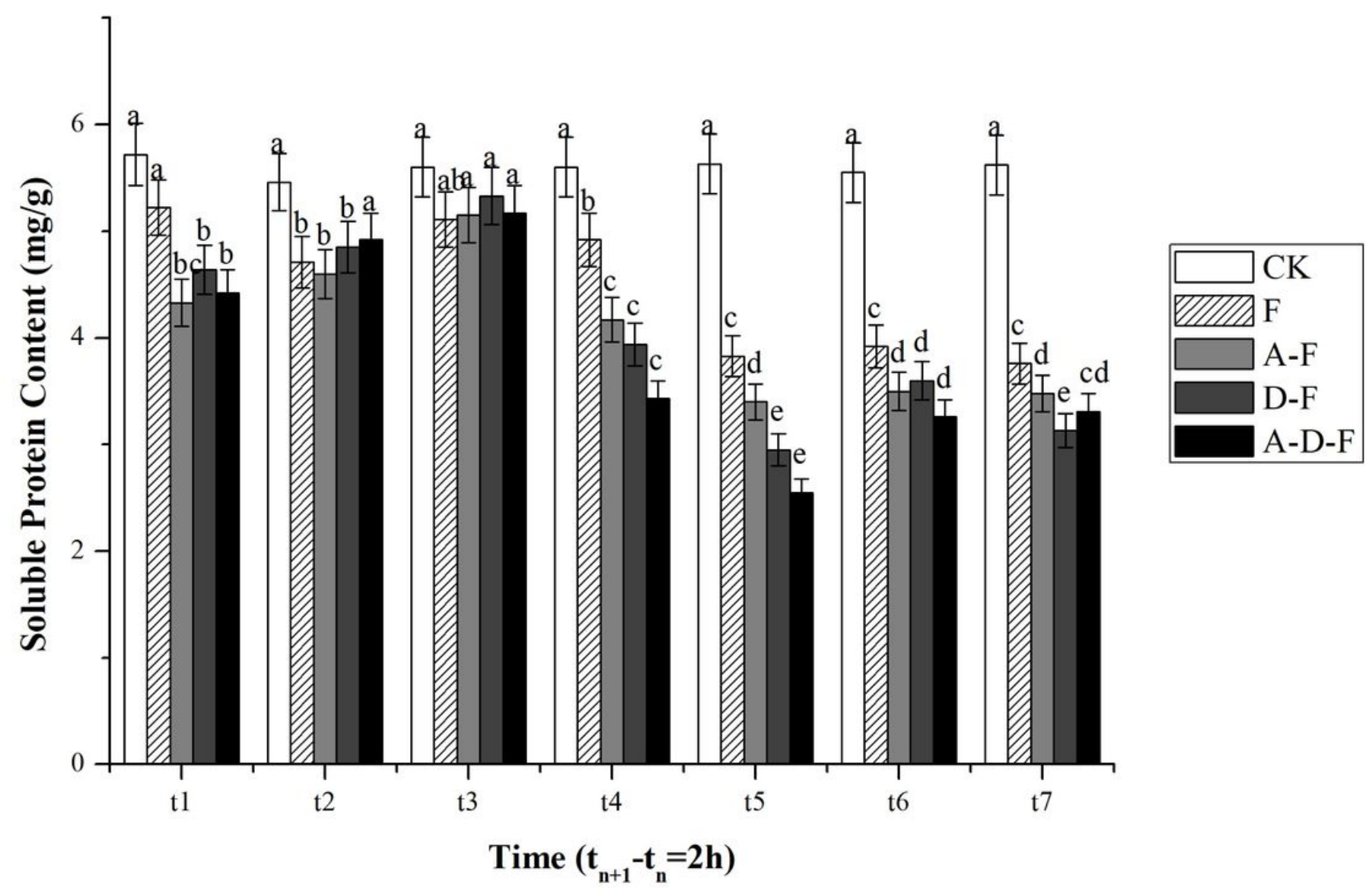

Figure 2

Combined effects of freeze-thaw, deicing salt and acid rain on the soluble protein content of alfalfa seedlings (mean $\pm S E, n=3$ ). $\mathrm{t} 1 \sim \mathrm{t} 7$ represents different $2 \mathrm{~h}$ temperature interval corresponding to 10,5 , $0,-5,0,5$, and $10^{\circ} \mathrm{C}$. CK represent blank group. The letter $A, D$ and $F$ represented acid rain treatment, deicing salt treatment and freeze-thaw treatment, respectively. The different letters indicate significant differences among the various treatments $(P<0.05)$. 


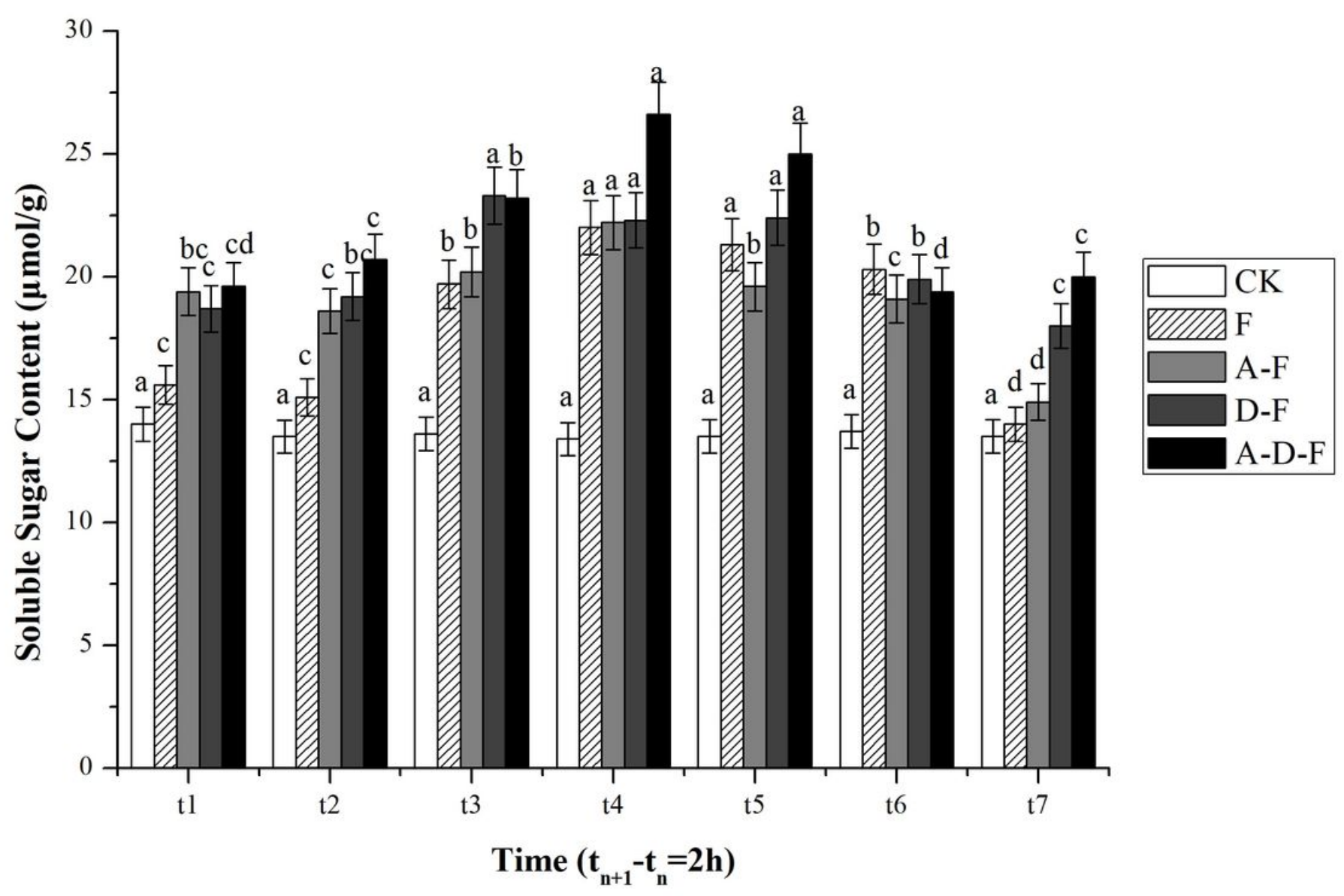

Figure 3

Combined effects of freeze-thaw, deicing salt and acid rain on the soluble sugar content of alfalfa seedlings (mean $\pm S E, n=3$ ). $t 1 \sim t 7$ represents different $2 \mathrm{~h}$ temperature interval corresponding to 10,5 , $0,-5,0,5$, and $10^{\circ} \mathrm{C}$. CK represent blank group. The letter $A, D$ and $F$ represented acid rain treatment, deicing salt treatment and freeze-thaw treatment, respectively. The different letters indicate significant differences among the various treatments $(P<0.05)$. 


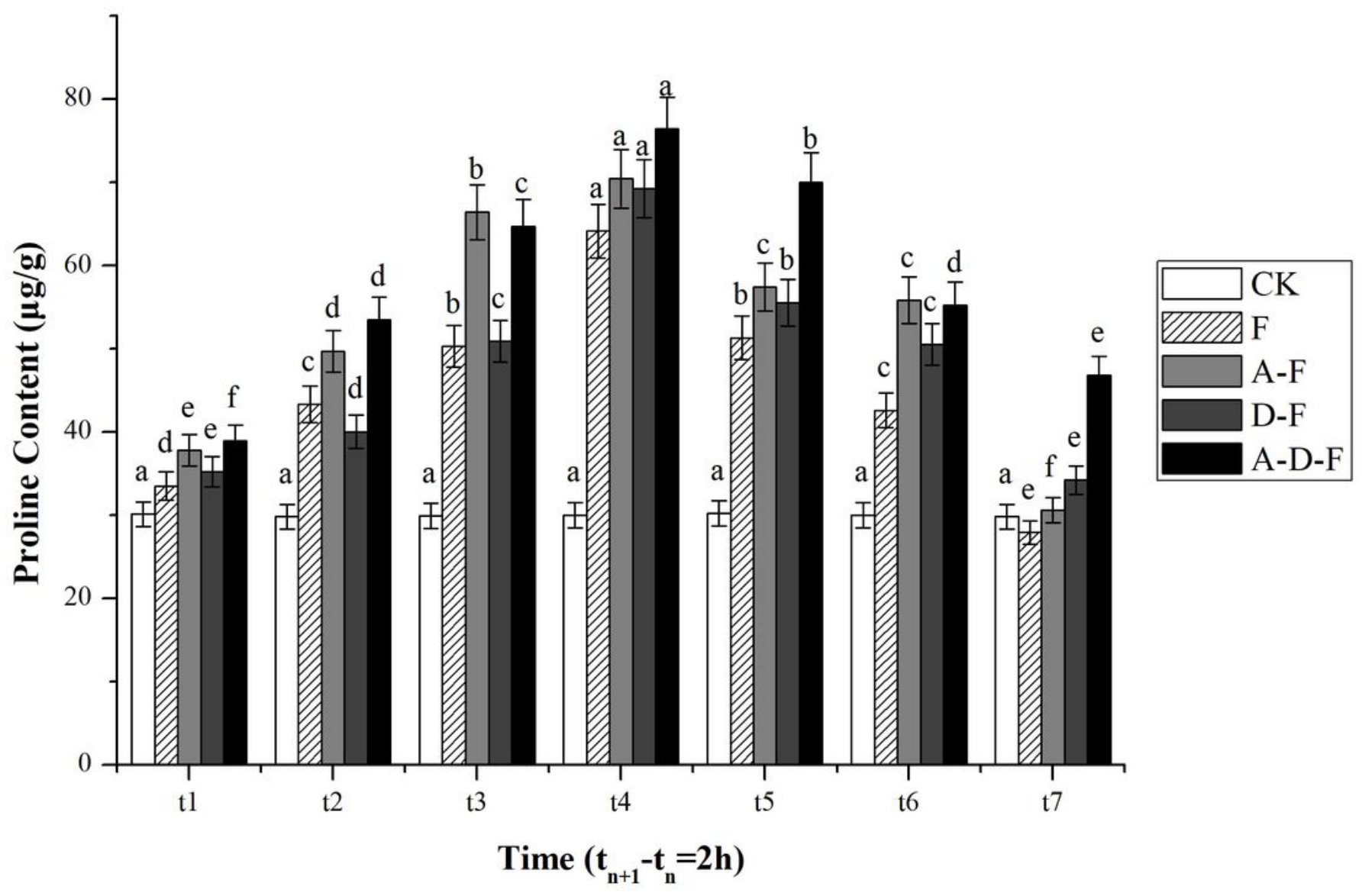

Figure 4

Combined effects of freeze-thaw, deicing salt and acid rain on the proline content of alfalfa seedlings (mean $\pm S E, n=3$ ). $\mathrm{t} 1 \sim \mathrm{t} 7$ represents different $2 \mathrm{~h}$ temperature interval corresponding to $10,5,0,-5,0,5$, and $10^{\circ} \mathrm{C}$. CK represent blank group. The letter $A, D$ and $F$ represented acid rain treatment, deicing salt treatment and freeze-thaw treatment, respectively. The different letters indicate significant differences among the various treatments $(P<0.05)$. 


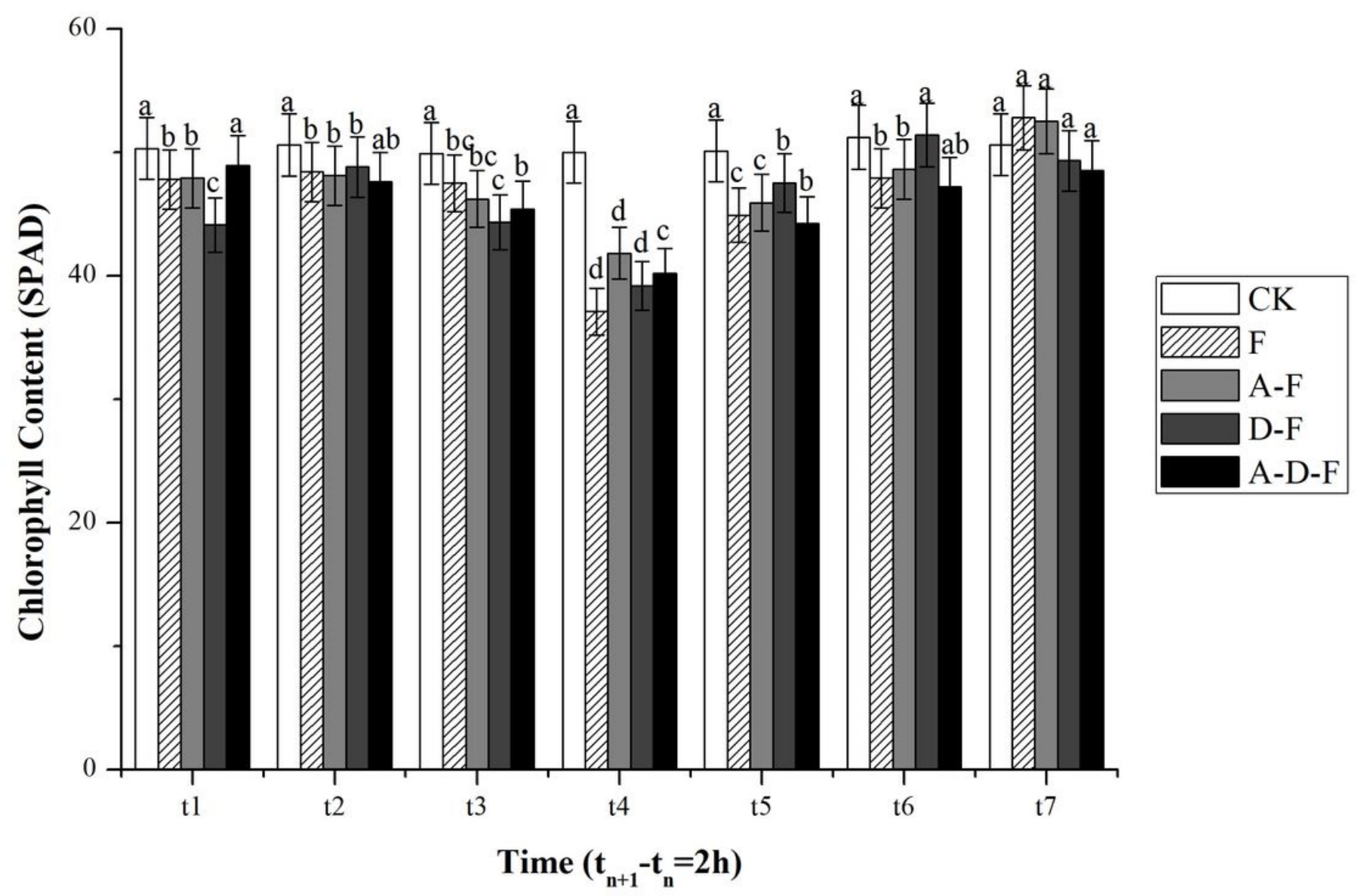

Figure 5

Combined effects of freeze-thaw, deicing salt and acid rain on the chlorophyll content of alfalfa seedlings (mean $\pm S E, n=3$ ). $\mathrm{t} 1 \sim \mathrm{t} 7$ represents different $2 \mathrm{~h}$ temperature interval corresponding to $10,5,0,-5,0,5$, and $10^{\circ} \mathrm{C}$. CK represent blank group. The letter $A, D$ and $F$ represented acid rain treatment, deicing salt treatment and freeze-thaw treatment, respectively. The different letters indicate significant differences among the various treatments $(P<0.05)$. 